\title{
A RT-PCR assay for the rapid recognition of border disease virus*
}

\author{
Štefan VILČEK ${ }^{\mathrm{a}}$, David J. PATON ${ }^{\mathrm{b} * *}$ \\ aUniversity of Veterinary Medicine, 04181 Kosice, Slovakia \\ ${ }^{b}$ Veterinary Laboratories Agency-Weybridge, Addlestone, Surrey KT15 3NB, UK
}

(Received 28 December 1999; accepted 30 March 2000)

\begin{abstract}
A reverse transcription - polymerase chain reaction (RT-PCR) method was developed for the specific detection of border disease virus (BDV), using the primers PBD1 and PBD2 flanking a 225 bp DNA fragment, selected from the 5'noncoding region of the pestivirus genome. In tests on 70 pestiviruses it was shown to be BDV-specific. A closed, one-tube nested RT-PCR method employing general pestivirus outer primers (324 and 326), and the same BDV-specific inner primers (PBD1 and PBD2) in conjunction with a BDV-specific fluorogenic TaqMan probe also detected only BDV and was more sensitive. BDV-specific RT-PCR was used in combination with a PCR specific for bovine viral diarrhoea virus type 2 (BVDV2) to ascertain whether virus stocks contained mixtures of BDV and BVDV2. It was shown that the ovine pestivirus strains 175375 and 59386 were originally BDV, but after subculture had become contaminated with BVDV2. This explains a previously reported discrepancy in the genetic typing of 59386. Although the BDV-specific RT-PCR can also detect BDV in clinical samples, the assay is likely to be most useful for the rapid typing of laboratory pestivirus strains.
\end{abstract}

\section{border disease virus / BDV / RT-PCR / typing / pestivirus contamination}

Résumé - Identification rapide du border disease virus par RT-PCR. Une méthode d'amplification en chaîne par polymérase après transcription inverse (RT-PCR) a été développée pour la détection spécifique du border disease virus (BDV), utilisant les amorces PBD1 et PBD2 flanquant un fragment d'ADN de $225 \mathrm{pb}$, choisi dans la région 5' non codante du génome des pestivirus. Des tests sur 70 souches de pestivirus ont démontré la spécificité de la méthode. Une méthode de RT-PCR nichée dans un seul tube fermé a également permis de détecter spécifiquement le BDV, tout en améliorant la sensibilité. Cette dernière méthode utilise des amorces externes générales pour les pestivirus (324 et 326), les amorces internes PBD1 et PBD2 ainsi qu'une sonde fluorogénique TaqMan reconnaissant spécifiquement le BDV. Les stocks de virus ont été testés à la fois par RT-PCR spécifique du BDV et RT-PCR spécifique du virus de la diarrhée bovine type 2 (BVDV2), afin de déterminer s'ils contenaient un mélange des deux virus. Il a ainsi été montré que les souches de pestivirus ovins 175375

\footnotetext{
* With the permission of Crown

** Correspondence and reprints

Tel.: (44) 1932 357285; fax: (44) 1932 357239; e-mail: dpaton.cvl.wood@gtnet.gov.uk
} 
et 59386 étaient initialement du BDV, mais ont été contaminées par du BVDV2 lors de cultures. Ceci explique les différences constatées dans les résultats de précédents typages génétiques de 59386. La RT-PCR peut être utilisée pour détecter du BDV dans des échantillons cliniques, mais elle est surtout utile pour le typage rapide des souches pestivirales en laboratoire.

\section{border disease virus / BDV / RT-PCR / typage génétique / contamination par pestivirus}

\section{INTRODUCTION}

Pestiviruses are enveloped, singlestranded RNA viruses which belong to the Flaviviridae family. At present the genus Pestivirus comprises bovine viral diarrhoea virus (BVDV), with two genotypes BVDV1 and BVDV2, classical swine fever virus (CSFV) and border disease virus (BDV). The term BDV is ambiguous, because it has also been used to refer to any ovine pestivirus which may include viruses of the BVDV genotypes. The nomenclature is therefore under re-consideration. All pestiviruses are important veterinary pathogens causing economic losses in cattle, pigs and sheep [10].

BDV is a causative agent of border disease of sheep which is characterised by abortion, stillbirth and birth of live but abnormal lambs characterised by the "hairy shaker" syndrome [12]. Although BDV infects mainly sheep, the virus can also cross the host-species barrier and infect pigs [18, 24]. Early antigenic analysis revealed that ovine pestiviruses can be divided into two groups which include BDV-like and BVDVlike strains [11]. Recently, it has been demonstrated that ovine pestiviruses are divided into BDV, BVDV1 and BVDV2, both at the antigenic and genetic level [3, $15,23,26]$. The difficulty of distinguishing between the pestivirus genotypes and their ability to cross host-species barriers emphasise the value of laboratory typing of pestivirus strains.

Laboratory detection of pestiviruses is usually based on virus isolation in cell culture and detection of viral antigens by immunoassay. Differentiation of CSFV from the other pestiviruses has been achieved using a panel of monoclonal antibodies against the CSFV major envelope protein [28]. Discrimination of BDV from other pestiviruses has been recently resolved with the development of BDV-specific monoclonal antibodies [14].

Several RT-PCR (reverse transcriptionpolymerase chain reaction) assays have been developed for the detection of all pestiviruses, or for the specific detection of BVDV and CSFV [4, 5, 7, 19, 25, 29]. However, there are few genetic assays for the specific detection of BDV. The first was a semi-nested RT-PCR assay using primers directed at the $\mathrm{E}^{\mathrm{rns}}$ gene which was validated on a limited number of BDV strains [20]. Another approach used nested RTPCR targeted at the conserved 5'noncoding region (5'NCR) of the genome to detect all pestiviruses, followed by BDV discrimination using a specific TaqMan fluorogenic probe [9].

Not many BDV have been analysed at the genetic level [2, 16, 18, 21, 24]. Recently, we have sequenced a broad range of ovine pestiviruses in the 5'NCR. Many of these were identified as BDV [26]. The sequence data provided new information for the selection of BDV-specific PCR primers. The aim of our work was to develop a RTPCR method for the specific detection of a broad range of BDV strains and to use it in the genetic typing of pestiviruses.

\section{MATERIALS AND METHODS}

\subsection{Viruses}

Seventy viruses were used in this study. These included 25 ovine pestiviruses typed 
at the genetic level as BDV [26], along with BDV strains Wisman [27] and Frijters [24] isolated from pigs. Also included were representative BVDV1 from sheep $(n=13$, [26]) and from cattle $(n=8$, i.e. four field isolates, reference strains NADL and Oregon $\mathrm{C} 24 \mathrm{~V}$, the UK isolate 4800 [15] and a divergent strain from Mozambique [1]). The BVDV2 genotype was represented by 9 isolates, from pigs (Vosges, Rutten; [15, 22]), sheep (Lees, 167237, 173157, 175375; [26]) and cattle (166312, 178003; [15] and reference strain 890). The ovine isolate 59386 has been typed as both a BVDV2 [2, 14, 15] and as a BDV [13]. A group of 11 CSFV was chosen as representative of phylogenetically divergent strains, varying in virulence, geographic origin and year of collection [7]. Finally, the virus collection included a deer pestivirus of uncertain classification [15].

To establish the sensitivity of RT-PCR assays, a ten-fold titration series was made in serum-free culture medium starting with a cell culture supernatant containing a known infectious dose of BDV G2048 [26]. Five clinical samples (blood or serum) were obtained from sheep in which clinical signs suspicious of pestivirus infection had been observed.

\subsection{Isolation of RNA and synthesis of cDNA}

Total RNA was extracted from virus-containing cell culture supernatants using a QIAamp Viral RNA purification kit (Qiagen, UK). Details of the procedure were described elsewhere [8]. Synthesis of cDNA was carried out using random primers [25].

\subsection{Single PCR}

For single PCR, two pairs of primers targeting the 5'NCR were used. The panpestivirus reactive 324 and 326 primers flank a 288 bp DNA fragment [25]. New BDV spe- cific PBD1 (5'- TCG TGG TGA GAT CCC TGA G-3') and PBD2 (5'- GCA GAG ATT TTT TAT ACT AGC CTA TRC-3') primers were targeted to the $324 \times 326$ DNA amplification product, flanking a $225 \mathrm{bp}$ fragment. A BVDV2 specific PCR was also used [17] employing primers designated here as RB21 (5'-CGA CAC TCC ATT AGT TGA GG-3') and RB22 (5',-GTC CAT AAC GCC ACG AAT AG-3').

The amplification mixtures $(50 \mu \mathrm{L})$ consisted of $5 \mu \mathrm{L} 10 \times$ reaction PCR buffer (Promega), $5 \mu \mathrm{L}$ of $25 \mathrm{mM} \mathrm{MgCl}_{2}, 1 \mu \mathrm{L}$ of $2 \mathrm{mM}$ each dNTP (Pharmacia), 15 pmol of each primer, $1 \mathrm{U}$ Taq DNA polymerase (Promega) and $3 \mu \mathrm{L}$ cDNA. In vitro amplifications were performed in a MJ thermocycler (Genetic Research Instrumentation Ltd, England) using the following thermal profile: denaturation at $94{ }^{\circ} \mathrm{C}$ for $1 \mathrm{~min}$, annealing for $1 \mathrm{~min}$ at $56^{\circ} \mathrm{C}$, extension at $72{ }^{\circ} \mathrm{C}$ for $1 \mathrm{~min}$. After 36 cycles the last extension step was prolonged for $7 \mathrm{~min}$.

\subsection{Closed one-tube nested RT-PCR}

This method employed the 324 and 326 primers and a second set of panpestivirus reactive inner primers (A11 and A14), as described by McGoldrick et al. [8, 9]. Alternatively, the inner primers were replaced by primers specific for BDV (PBD1 and PBD2) or BVDV2 (RB1 and RB2, [17]). In some RT-PCR experiments the amplification product was hybridised to TaqMan fluorogenic probes specific for BDV or BVDV2 [9].

\subsection{Sequencing of PCR products and computer-assisted analysis}

PCR products were sequenced in both directions with the primer pairs $324 \times 326$ or PBD1 $\times$ PBD2 using an ABI PRISM sequencing device, based on the incorporation of fluorescent labelled dideoxynucleotide terminators. Thereafter, nucleotide 
sequences were aligned by the multiple program DNASTAR (DNASTAR, Inc., Madison, USA) using a Clustal method. A dendrogram was prepared using the MegAlign program of the DNASTAR package, based on a distance matrix method.

\section{RESULTS}

The specificity of the new primers PBD1 $\times$ PBD2 for BDV was tested on a panel of 27 phylogenetically distinct BDV, 21 BVDV1, 9 BVDV2, $11 \mathrm{CSFV}$, an unclassified deer pestivirus, and isolate 59386 of uncertain provenance. After RT and a single round of PCR, specific amplification of a $225 \mathrm{bp}$ DNA product was achieved with all BDV. No PCR product was detected with other pestiviruses (Fig. 1A), apart from the BVDV2 isolate 175375 and isolate 59386. The BDV-specific PCR primers could also recognise the Frijters and Wisman strains (Fig. 1B), which were isolated from pigs but previously typed as BDV strains. The same specificity was observed for the BDV primers when they were used in a one tube nested RT-PCR assay $(324 \times 326$ - outer primers;
PBD1 $\times$ PBD2 - inner primers) with a BDV-specific fluorogenic hybridisation probe (data not shown).

The sensitivity study revealed a detection limit for the single RT-PCR assay of $2 \times 10^{2} \mathrm{TCID}_{50} \cdot \mathrm{mL}^{-1}$. However, the modified closed one-tube nested RT-PCR with the TaqMan BDV fluorogenic probe was 10 times more sensitive.

Conflicting results were obtained in the amplification of the ovine pestiviruses 175375 and 59386. As expected, a 288 bp DNA fragment was amplified using the general pestivirus primers 324 and 326 . These isolates also provided a faint 225 bp PCR product after a single RT-PCR using the BDV-specific PBD1 and PBD2 primers (Fig. 2B, and barely visible in Fig. 2A). For 175375, the DNA product obtained after one-tube nested RT-PCR using panpestivirus primers $(324 \times 326$ and A11 $\times$ A14 $)$ was identified only with a TaqMan BVDV2specific hybridisation probe. However, in the case of 59386, only the BDV-specific probe detected the product of nested panpestivirus-specific PCR. A comparison of sequences derived from DNA products obtained from the two single RT-PCR
A

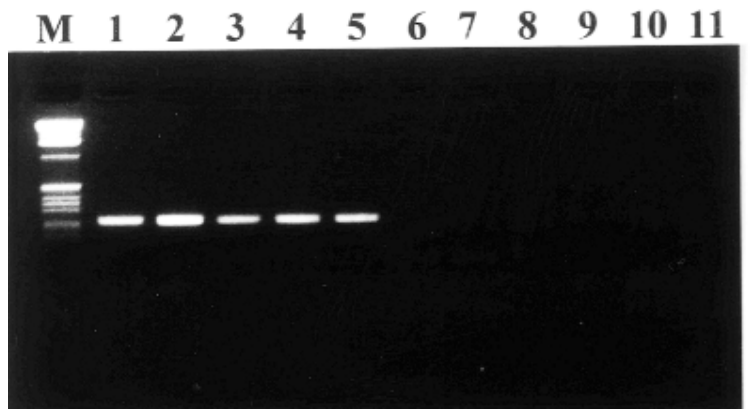

B

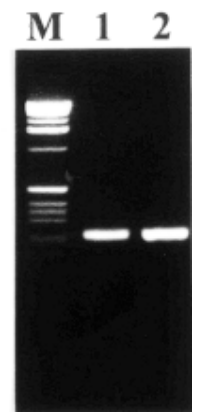

Figure 1. Typing of laboratory pestivirus strains by a RT-PCR method using the PBD1 $\times$ PBD2 primers. A/ Lanes: 1-5: BDV strains; 6, 7: BVDV1 strains; 8, 9: CSFV strains; 10, 11: BVDV2 strains; M: 1kb ladder (Gibco) ; B/ lanes: 1: Frijters; 2: Wisman; M: 1 kb ladder (Gibco). 
A

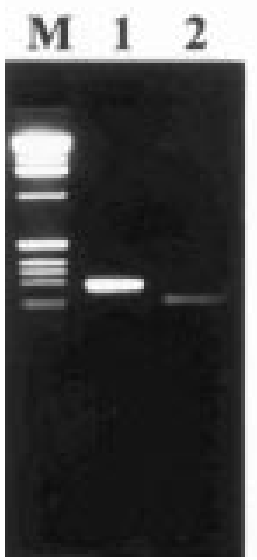

B

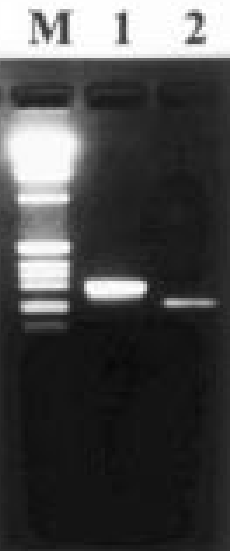

Figure 2. Genetic typing of the ovine 175375 and 59386 strains. Electrophoretic analysis of single RT-PCR products of 175375 (A) and 59386 (B) strains obtained with the $324 \times 326$ (lanes 1 ) or PBD1 $\times$ PBD2 primers (lanes 2 ). M: $1 \mathrm{~kb}$ ladder (Gibco). methods (Fig. 2A) revealed that the 175375 strain was typed as BVDV2 (amplification with $324 \times 326$ primers) or as a BDV (amplification with PBD1 $\times$ PBD2 primers). In contrast, the amplicons of the 59386 isolate (Fig. 2B) were BDV-like in sequence after both amplifications. Figure 3 is a phylogenetic tree showing the relationship between different sequences obtained from amplicons of the ovine pestiviruses 175375 , 59386 and 173157 , as well as to reference strains of pestiviruses from the four genotypes.

This led us to check different cell culture passages of these two viruses (Tab. I). All passages tested were strongly positive in a single RT-PCR with panpestivirus $324 \times$ 326 primers as well as with BDV-specific PBD1 $\times$ PBD2 primers. All were negative in a single RT-PCR with the BVDV2 specific RB21 $\times$ RB22 primers (Tab. I). Therefore, in order to reveal even a small amount of BVDV2 in the different stocks, we used the one-tube nested RT-PCR with panpestivirus $324 \times 326$ outer primers and with BVDV2

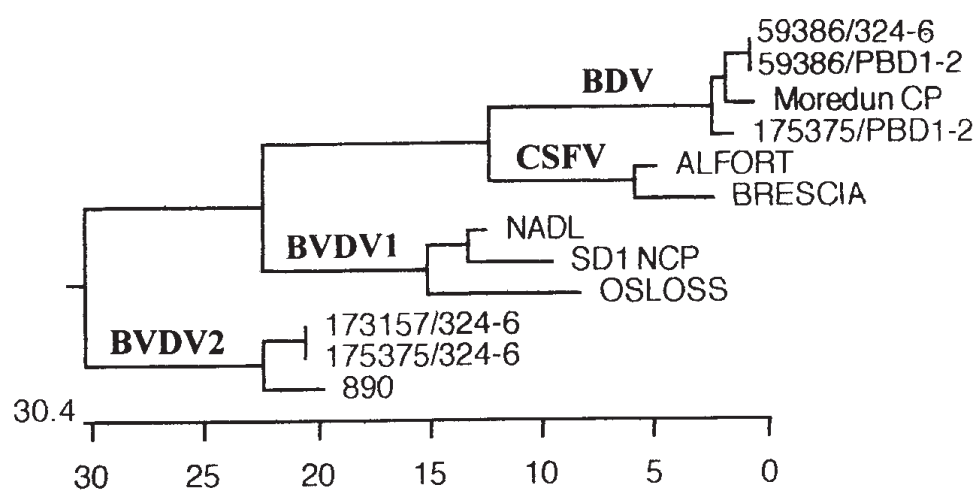

Figure 3. Dendrogram showing the relationship between different amplicons and their genotype. Nucleotide sequences for strains 175375,59386 and 173157 were obtained by sequencing of RT-PCR products using $324 \times 326$ or PBD1 $\times$ PBD2 primers. Sequences for the reference pestivirus strains were obtained from GenBank. 
Table I. Detailed RT-PCR analysis of the ovine pestiviruses 175375 and 59386.

\begin{tabular}{|c|c|c|c|c|}
\hline \multirow[b]{2}{*}{ Sample } & \multicolumn{3}{|c|}{ Single RT-PCR ${ }^{2}$} & \multirow{2}{*}{$\begin{array}{c}\text { Nested } \\
\text { RT-PCR } 2 \\
324 \times 326 \\
\text { RB2 } 1 \times \text { RB22 }\end{array}$} \\
\hline & $324 \times 326$ & PBD1 $\times$ PBD2 & $\mathrm{RB} 21 \times \mathrm{RB} 22$ & \\
\hline \multicolumn{5}{|l|}{ Ovine pestivirus 175375} \\
\hline 1st passage (9 June, 1987) ${ }^{1}$ & +++ & +++ & - & - \\
\hline 2nd passage (21 July, 1987) & +++ & +++ & - & + \\
\hline 2nd passage (19 Nov., 1988) & +++ & +++ & - & - \\
\hline $\begin{array}{l}\text { 3rd passage (28 Feb., 1991, } \\
\text { from 2nd passage, } 21 \text { July 1987) }\end{array}$ & +++ & +++ & - & +++ \\
\hline \multicolumn{5}{|l|}{ Ovine pestivirus 59386} \\
\hline 1st passage (9 June, 1987$)^{1}$ & +++ & +++ & - & - \\
\hline 2nd passage (27 April, 1993) & +++ & +++ & - & - \\
\hline 2nd passage (21 July, 1987) & +++ & +++ & - & + \\
\hline $\begin{array}{l}\text { 3rd passage (29 June, 1993, } \\
\text { from 2nd passage, } 21 \text { July, 1987) }\end{array}$ & +++ & +++ & - & +++ \\
\hline
\end{tabular}

${ }_{1}^{1}$ Original sample not available.

${ }^{2}$ Specificity of the primers: $324 \times 326$ are panpestivirus specific, PBD1 $1 \times$ PBD2 are BDV-specific, RB2 $1 \times$ RB22 are BVDV2-specific.

specific RB21 $\times$ RB22 inner primers. In this experiment, the first cell culture passages of 175375 and 59386 (original samples were not available) were negative for BVDV2. However, analysis after one or two further passages showed that the samples had become slightly positive for BVDV2. PCR products were strongly positive for BVDV2 when testing the third passages of both strains.

To test the new BDV primers for their capacity to detect BDV directly in clinical samples, five blood samples were analysed that had been obtained from sheep with signs suggestive of a pestivirus infection. The virus was detected in all samples tested (Fig. 4). The specificity of the in vitro amplification was confirmed by sequencing the PCR products, revealing that BDV was present in all five clinical samples.

\section{DISCUSSION}

Although many RT-PCR assays have been developed for the detection of pes- tiviruses, only a few of them specifically detected BDV $[9,20]$. The main difficulty in designing such assays has been the lack of nucleotide sequence data available for BDV, either in the literature or in international databases. The BDV-specific primers used in this work originate from the evolutionarily conserved $5^{\prime} \mathrm{NCR}$ of the pestivirus genome. Their selection has been made by the alignment of 43 ovine pestivirus sequences from the $5^{\prime} \mathrm{NCR}$, including $25 \mathrm{BDV}$ isolates representing the two main phylogenetic subgroups [26]. The specificity of the new primers was confirmed by the detection of all 27 BDV strains from amongst a total of 70 pestiviruses using a single RT-PCR. In a nested RT-PCR employing the $324 \times 326$ outer and PBD $1 \times$ PBD2 inner primers, we observed cross reactivity with other pestiviruses, especially with some CSFV strains (data not shown). This could be eliminated, by incorporating a TaqMan BDV-specific fluorogenic probe, according to the closed one-tube nested RT-PCR method developed by McGoldrick et al. [9]. 


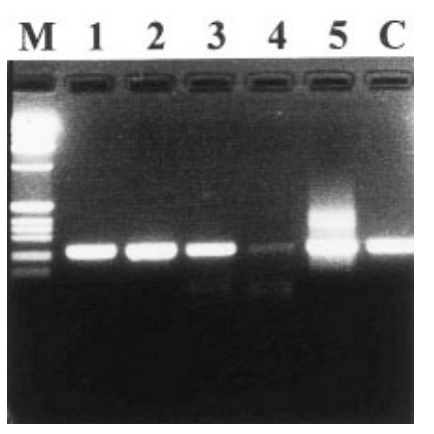

Figure 4. Use of the PBD1 $\times$ PBD2 primers for RT-PCR on clinical samples. Clinical samples (blood and serum) from diseased sheep (lanes 1-5), C: positive control, M: 1 kb ladder (Gibco).

Conflicting results were obtained with the two ovine pestiviruses, 175375 and 59386, and this was shown to be due to contamination of the original BDV stocks with BVDV2. Previously, the virus 175375 had been typed as a BVDV2 [14, 26], whilst isolate 59386 had been typed on different occasions as either a BVDV2 [2, 14, 15] or as a BDV [13]. The products obtained after single PCR with panpestivirus-specific primers $(324 \times 326)$ gave unambiguous sequences not suggestive of a mixed virus population. In the case of 175375 an amplicon with a BVDV2 sequence was obtained, whereas with 59386, the sequence was of BDV. Similar results were obtained using a nested pan-pestivirus-specific PCR followed by application of fluorogenic probes specific for either BDV or BVDV2. A mixed virus population was not detected by this approach, since only one probe recognised the amplified product, BVDV2 being detected in 175375 and BDV in 59386. However, use of our BDV-specific primers, along with amplicon sequencing, confirmed that BDV was present in stocks of both viruses.
These results suggested that 175375 contained a mixture of BDV and BVDV2. Probably, the level of BDV was very low, so that the non-discriminatory panpestivirus primers $(324 \times 326$, A11 $\times$ A14 $)$ had predominantly amplified the majority species i.e. BVDV2. In contrast the BDV-specific primers being only able to amplify BDV picked out the low level present. Alternatively, the panpestivirus-specific primers preferentially amplify BVDV2 rather than BDV. The results for 59386 did not at this stage indicate the presence of BVDV2 at all, arguing against preferential BVDV2 amplification by panpestivirus-specific primers, since previous studies clearly indicated that this virus did contain BVDV2. For example, monoclonal antibodies raised against this virus have been shown to be BVDV2-specific [14]. To explain the origin of two pestiviruses within a single viral sample, we speculated that the original viral strain could have become contaminated with BVDV2 during cultivation of the virus in cell culture. Such contamination has been demonstrated for many culture systems and foetal calf serum samples [6]. To investigate this possibility, experiments were established to check stocks obtained from different passages of these two viruses. In the case of the virus 175375 , the first passage was positive only with BDV specific PBD1 $\times$ PBD2 primers, whilst by the third passage, the virus had become highly positive for BVDV2. A similar situation was observed with the 59386 strain. We suppose that the origin of BVDV2 in both viral strains examined is most probably foetal calf serum used for the cultivation. The same stock of foetal calf serum could have contaminated both viruses when they were sub-passaged on the same day (21st July 1987 - Tab. I). The results clearly demonstrate that it is very important to know the detailed passage history of virus strains used for typing studies.

Although the RT-PCR assay with BDV specific primers can also be used for the detection of BDV in clinical samples, the most practical use of the PBD1 $\times$ PBD2 
primers is likely to be in a single RT-PCR assay for rapid typing and confirmation of BDV in laboratory pestivirus strains.

\section{ACKNOWLEDGMENTS}

Thanks are due to G. Ibata for preparation of viruses. Š. Vilček was supported by an International Fellowship from The Wellcome Trust (grant no. 049929/Z/96/Z). D. Paton was supported by MAFF project OD0326.

\section{REFERENCES}

1] Baule C., van Vuuren M., Lowings J.P., Belak $\mathrm{S}$, Genetic heterogeneity of bovine viral diarrhoea viruses isolated in Southern Africa, Virus Res. 52 (1997) 205-220.

[2] Becher P., Konig M., Paton D.J., Thiel H.-J., Further Characterization of border disease virus isolates: Evidence for the presence of more than three species within the genus pestivirus, Virology 209 (1995) 200-206.

[3] Becher P., Orlich M., Shannon A.D., Horner G., Konig M., Thiel H.-J., Phylogenetic analysis of pestiviruses from domestic and wild ruminants, J. Gen. Virol. 78 (1997) 1357-1366.

[4] Canal C.W., Hotzel I., DeAlmeida L.L., Roehe P.M., Masuda A., Differentiation of classical swine fever virus from ruminant pestiviruses by reverse transcription and polymerase chain reaction (RT-PCR), Vet. Microbiol. 48 (1996) 373379.

[5] Katz J.B., Ridpath J.F., Bolin S.R., Presumptive diagnostic differentiation of hog cholera virus from bovine viral diarrhea and border disease viruses by using a cDNA nested-amplification approach, J. Clin. Microbiol. 31 (1993) 565-568.

[6] Levings R.L., Wessman S.J., Bovine viral diarrhea virus contamination of nutrient serum, cell cultures and viral vaccines, Dev. Biol. Stand. 75 (1991) 177-181.

[7] Lowings J.P., Ibata G., Needham J., Paton D.J., Classical swine fever diversity and evolution, J. Gen. Virol. 77 (1996) 1311-1321.

[8] McGoldrick A., Lowings J.P., Ibata G., Sands J.J., Belák S., Paton D.J., A novel approach to the detection of classical swine fever virus by RT-PCR with a fluorogenic probe (TaqMan), J. Virol. Methods 72 (1998) 125-135.

[9] McGoldrick A., Bensaude E., Ibata G., Sharp G., Paton D.J., Closed one-tube reverse transcriptase polymerase chain reaction for the detection of pestiviral RNA with fluorescent probes. J. Virol. Methods 79 (1999) 85-95.
[10] Moennig V., Plagemann G.W., The pestiviruses, Adv. Virus Res. 41 (1992) 53-98.

[11] Nettleton P.F., Pathogenesis and epidemiology of border disease, Ann. Rech. Vét. 18 (1987) 147155.

[12] Nettleton P.F., Gilray J.A., Russo P., Dlissi E., Border disease of sheep and goats, Vet. Res. 29 (1998) 327-340.

[13] Paton D.J., Pestivirus diversity, J. Comp. Pathol. 112 (1995) 215-236

[14] Paton D.J., Sands J.J., Edwards S., Border disease virus: delineation by monoclonal antibodies, Arch. Virol. 135 (1994) 241-252.

[15] Paton D.J., Sands J.J., Lowings J.P., Smith J.E., Ibata G., Edwards S., A proposed division of the pestivirus genus using monoclonal antibodies, supported by cross-neutralisation assays and genetic sequencing, Vet. Res. 26 (1995) 92-109.

[16] Ridpath J.F., Bolin S.R., Comparison of the complete genomic sequence of the border disease virus, BD31, to other pestiviruses, Virus Res. 50 (1997) 237-243.

[17] Ridpath J.F., Bolin S.R., Differentiation of types $1 \mathrm{a}, 1 \mathrm{~b}$ and 2 bovine viral diarrhoea virus (BVDV) by PCR, Mol. Cell. Probes 12 (1998) 101-106.

[18] Roehe P.M., Woodward M.J., Edwards S., Characterization of p20 gene sequences from a border disease-like pestivirus isolated from pigs, Vet. Microbiol. 33 (1992) 231-238.

[19] Sandvik T., Paton D.J., Lowings P.J., Detection and identification of ruminant and porcine pestiviruses by nested amplification of 5' untranslated cDNA regions, J. Virol. Methods 64 (1997) 43-56.

[20] Sullivan D.G., Akkina R.K., A nested polymerase chain reaction assay to differentiate pestiviruses, Virus Res. 38 (1995) 231-239.

[21] Sullivan D.G., Chang G.J. Akkina R.K., Genetic characterization of ruminant pestiviruses: sequence analysis of viral genotypes isolated from sheep, Virus Res. 47 (1997) 19-29.

[22] Terpstra C., Wensvoort G., Natural infection of pigs with bovine viral diarrhoea virus associated with signs resembling swine fever, Res. Vet. Sci. 45 (1988) 137-142.

[23] van Rijn P.A., van Gennip H.G.P., Leendertse C.H., Bruschke C.J.M., Paton D.J., Moormann R.J.M., van Oirschot J.T., Subdivision of the pestivirus genus based on envelope glycoprotein E2, Virology 237 (1997) 337-348.

[24] Vilček Š., Belák S., Genetic identification of pestivirus strain Frijters, isolated from pigs, as a border disease virus, J. Virol. Methods 60 (1996) 103-108.

[25] Vilček Š., Herring A.J., Herring J.A., Nettleton P.F., Lowings J.P., Paton D.J., Pestiviruses isolated from pigs, cattle and sheep can be allocated into at least three genogroups using polymerase chain reaction and restriction endonuclease analysis, Arch. Virol. 136 (1994) 309-323. 
[26] Vilček S., Nettleton P.F., Paton D.J., Belák S., Molecular characterization of ovine pestiviruses, J. Gen. Virol. 78 (1997) 725-735.

[27] Wensvoort G., Terpstra C., Bovine viral diarrhoea virus infection in piglets born to sows vaccinated against swine fever with contaminated vaccine, Res. Vet. Sci. 45 (1998) 143-148.

[28] Wensvoort G., Terpstra C., De Kluijver E.P., Kragten C., Warnaar J.C., Antigenic differenti- ation of pestivirus strains with monoclonal antibodies against hog cholera virus, Vet. Microbiol. 21 (1989) 9-20.

[29] Wirz B., Tratshin J.D., Muller H.K., Mitchell D.B., Detection of hog cholera virus and differentiation from other pestiviruses by polymerase chain reaction, J. Clin. Microbiol. 31 (1993) 11481154. 